\title{
Experimenteller Beweis der Möglichkeit der Selbstentzündung des Heues (Grummets)*);
}

\section{von H. Ranke.}

In einem auf Anfragen eines kgl. bayr. Bezirksgerichtes 1872 vom kgl. Medicinalcomité der Universität Mürichen durch Professor L. A. B u chner als Referenten erstatteten Bericht über die Selbstentzündlichkeit des Heues wird gesagt, dafs eine solche Selbstentzündung, wenn auch bis jetzt nicht ganz unzweifelhaft festgestellt, doch vom wissenschaftlichen Standpunkt aus keineswegs unmöglich erscheine. Es wird hervorgehoben, dafs das Heu, wenn es in feuchtem Zustand eingebracht und in grofse Haufen aufgeschichtet wird, in eine Art Gährung übergeht, welche von beträchtlicher Wärmeentwickelung begleitet ist; dann heifst es weiter :

"Wenn nun eine freiwillige Zersetzung feuchten Heues und als Folge derselben eine bedeutende Wärmeentwickelung als wohl constatirt angenommen werden mufs, so läfst sich auch denken, dafs, wenn der gröfste Theil des im Futter enthaltenen Wassers verdampft ist, durch fortgesetzte Sauerstoffanziehung und Verwesung unter besonders günstigen Bedingungen die Hitze bis zur Entflammung gesteigert werden könne. Es läfst sich nämlich denken, dafs bei erwähnter fortschreitender Zersetzung das Heu eine Art Verkohlung erleide und dafs die auf solche Weise gebildete kohlige Masse, ähnlich mancher andern Kohle, z. B. mancher Torfkohle oder mit Kohle gemengter Torfasche, oder auch ähnlich mancher mit feinzertheiltem Schwefelkies gemengter Steinkohle oder Braunkohle vermöge grofser Porosität und eingernengter, zur raschen

*) Aus der Zeitschrift des landwirthschaftlichen Vereins in Bayern Märzheft 1873 vom Vexfusser mitgetheilt. 
Sauerstoffanziehung und Oxydation geneigter Stoffe die Eigenschaft eines Pyrophors erhielte, bei gehörigem Zutritt von Luft diese rasch auf ihrer Oberflache in so hohem Grade zu verdichten, dafs dadurch die Masse ins Glühen kommt und verbrennt."

Wie es nun der Zufall wollte, bot sich mir noch im Verlaufe desselben Jahres Gelegenheit, die in vorstehendem Gutachten aufgestellte Ansicht Buchner's, welche das Medicinal-Comité zu der seinigen gemacht hatte, an einem praktischen Falle zu erproben und ihre Richtigkeit auch experimentell zu erweisen.

Auf meinem 4 Poststunden südlich von München am Grünwalder Forste gelegenen Gute Laufzorn bemerkte man am 19. October 1872 Morgens in der westlichen Ecke der grofsen, massiv gebauten Scheune brenzlichen Geruch.

In dieser Scheunenabtheilung lagerte ein Theil des auf dem Gute eingcheimsten Grummets, und zwar in zwei dicht aneinander gelagerten Haufen, wovon der eine ca. 450 Ctr., der andere ca. $300 \mathrm{Ctr}$. enthielt.

Dieses Grummet war sämmtlich in den Tagen vom 5. bis 10. August bei vortrefflichem $W$ etter und in anscheinend gut getrocknetem Zustande eingeerntet worden. Den ganzen September hindurch hatte sich daran der gewöhnliche stark aromatische Heugeruch bemerkbar gemacht, der an Intensität zunahm, am 17. und 18. October aber einem deutlich brenzlichen Geruche Platz machte.

Dieser brenzliche, brandige Geruch war am Sonnabend den 19. October Morgens so stark geworden, dafs mein Verwalter die Ueberzeugung gewann, es habe sich der Stock im Inneren entzündet.

Er beschlofs sofort, den Stock vorsichtigst abräumen zu lassen und, wenn man auf Feuer kommen sollte, mit grofsen Massen Wasser zu übergiefsen. 
Es wurden also alle verfügbaren Kübel, Fässer und sonstigen Wasserbehälter auf das Gebälke der Scheune über dem Grummet gebracht und Morgens $10^{1 / 2}$ Uhr mit vorsichtigem Abräumen begonnen.

Offenbar ging der Brandgeruch nur von dem gröfseren der beiden oben bezeichneten Haufen aus. Dieser Haufen (Stock) war nach Westen und Süden hin von solidem, $2^{\prime}$ dickem Mauerwerk bis zu einer Höhe von 17' umgeben, während die nach Osten gerichtete Seite nach der Tenne hin frei lag und die nach Norden gelegene unmittelbar in den kleinen Haufen überging.

Die Dimensionen des grörseren Haufens waren folgende : Höhe 23', Länge 23', Tiefe 16 '

An den oberen Partiecn schwitzte das Grummet stark, so zwar, dafs förmliche Tropfen an den Grashalmen hingen. Die Farbe des ganzen Stockes, soweit man denselben von Aufsen sehen konnte, war schön grün und man konnte von Aufsen keine Temperaturerhöhung an demselben wahrnehmen.

Das Abräumen wurde nun so vorgenommen, dafs hauptsächlich nach der Seite der Tenne hin das Grummet vorsichtig weggenommen und aus der Scheune gefahren wurde. Von oben wurden nur die schwitzenden Partieen bis in eine Tiefe von ca. $3^{\prime}$ abgeräumt; als man in dieser Tiefe auf trockenes und sehr heifses Grummet kam, wurde zunächst von der Höhe nichts mehr entfernt. Bei dem Abräumen von der Seite nach der Tenne hin machte sich in einer Tiefe von ungefähr $11 / 2^{\prime}$, nach dem Centrum des Stockes hin, zunehmende Wärme bemerkbar. Der Geruch, welcher bei dieser Arbeit dem Stocke entströmte, war stark brenzlich.

Als nun auch von oben kecker abgeräumt wurde, kamen plötzlich in einer ungefähren Tiefe von $5^{\prime}$ von oben einzelne Funken zum Vorschein. Gleichzeitig bemerkte man auf einem Wagen, auf welchem die letztabgeräumten Partieen Grummet 
aus der Scheune gefahren werden sollten, plötzlich an mehreren Stellen Rauch und Funkensprüben. Diefs war ungefähr 11/2 Uhr Nachmittags.

Es wurde nun der ganze Stock und eben so der beladene Wagen mit Wasser übergossen und das aus der Scheune gefahrene, tief dunkelbraun gefärbte Grummet auf dem Grasboden in der Nähe des hinter der Scheune gelegenen Weihers ausgebreitet.

Das Abräumen konnte von jetzt an, da bei dem Herausnehmen fast jeder Gabel voll Grummet Gluth zum Vorschein kam, nur unter beständigem Aufgiefsen von Wasser fortgesetzt werden. Auch war es sehr häufig nöthig. das schon auf Wagen geladene nochınals mit Wasser zu übergiefsen, da wiederholt selbst Bretter des Wagens in Brand geriethen. Ja selbst das schon auf dem Grasboden am Weilier Ausgebreilete entzündete sich oftmals von Neuem, so dafs hier zum dritten Male gelöscht werden mufste. Hier im Freien kam es auch wiederholt zu offener Flamme, deren Entwickelung innerhalb der Scheune wohl durch energisches Uebergiefsen hintangehalten wurde.

Es mag sogleich an dieser Stelle erwähnt werden, dafs am folgenden Tage die Grasnarbe überall, wo solches Grummet ausgebreitet worden war, sich vollkommen verbrannt zeigte.

An der Seite des in Brand gerathenen Stockes befand sich der bereits oben erwähnte, aus ca. $300 \mathrm{Ctr}$. bestehende Haufen. Dieser war vollkommen gut erhalten. Uin letateren von ersterem zu trennen, war es nöthig zwischen beiden einen Ausschnitt zu machen. Dieser Ausschnitt wurde in einer Breite von ca. $3 \frac{1}{2}{ }^{\prime}$ angelegt.

Bei dieser Arbeit fand eine so gewaltige Gasausströmung, wahrscheinlich von Kohlenoxydgas, statt, dafs es kein Arbeiter länger als 1 bis 2 Minuten dabei aushielt. Die Arbeiter kamen stets blafs und livid, mit dem Gefühle des Erstickens und nach Luft schnappend heraus.

Endlich, nach schon eingebrochener Dunkelheit, war man mit dem Ausräumen der glühenden Massen aus der Scheune fertig geworden.

Die in Gluth gerathene Masse des Stockes hatte gewissermafsen den Kern desselben gebildet, und mochte oben ca. 11' im Durchmesser betragen haben, und hatte nach unten bis etwa $1 \frac{1}{2}$ vom Boden gereicht, hier aber hatte sich die Gluth bis auf einen Durchmesser von ca. 4 bis $5^{\prime}$ verjüngt. Nach rückwärts, gegen die Rückmauer der Scheune hin, reichte dic Gluth bis ca. $1 \frac{1}{z^{\prime}}$ vou Mauerwerk. 
Der Zustand der glühenden Massen war der einer wirklichen Kohle mit Erhaltung der Structur. Man konnte noch jedes Grasblättcheu, jede Blüthe in ihrer Form deutlich erkennen. Zerrieb man diese Graskohle auf weilsem Papier, so wurde letzteres geschwärzt.

Wenn wir nun diese Erfahrungen im Lichte obigen Gutachtens betrachten, so ergiebt sich offenbar eine wesentliche Uebereinstimmung des Beobachteten mit den dort niedergelegten Anschauungen.

"Es läfst sich denken", hiefs es im Gutachten, „dafs bei erwähnter fortschreitender Zersetzung das Heu eine Art Verkohlung erleide, und dafs die auf solche Weise gebildete kohlige Masse ähnlich mancher anderen Kohle. . . . . vermöge grofser Porositäl und eingemengter, zur raschen Sauerstoffanziehung und 0xydation geneigter Stoffe die Eigenschaft eines Pyrophors erhalte, bei gehörigem Zutritt von Luft diese rasch auf ilhrer Oberfläche in so hobem Grade $\mathrm{zu}$ verdichten, dafs die Masse ins Glühen kommt und verbrernnt."

Wir haben aber eben gesehen, dafs in dem Laufzorner Falle sich eine wirkliche, Papier schwärzende Kohle aus einem Theile des Grummets gebildet hatte. Auch deutete das so häufige Wiederausbrechen des Feuers, wie dieses in obiger Schilderung so oft erwähnt ist, mit grofser Wahrscheinlichkeit darauf hin, dafs bei freiem Lufizutritt in der That eine Selbstentzündung dieser Grummetkohle durch mächtige Sauerstoffanziehung slattgehabt habe.

Ich suchte nun dieser letzteren Erscheinung auch experimentell näher zu treten. Mein Gedankengang war hierbei folgender :

Die Grummetkohle im erkalteten Zustande hat offenbar keine pyrophoren Eigenschaften*), es ist aber möglich, dafs man derselben ihre pyrophoren Eigenschaften wiedergeben kann, wenn man sie auf eine bestimmte hohe Temperatur bringt und dann dem freien Luftzutritt aussetzt.

Die ersten einschlägigen Versuche machte ich im Laboratorium des Herrn Prof. L. A. B uchner, spätere im Laboratorium des Herrn Geheimrath Freiherrn von Li e big und ist es mir eine angenehme Pflicht, beiden genannten Herren für deren überaus freundliche Unterstützung meinen aufrichtigen Dank zu sagen.

*) Ich hatte gröfsere Mengen derselben aufbewahrt und auch Herrn Geheimerath Freiherm von Liebig, Hern Prof. L. A. Buch ner und Herm Prof. Julius Lehmann Proben davon für die Sammlungen ihrer resp. Laboratorien übergeben. Alle diese Proben verhielten sich wie ganz gewölnliche ${ }_{n}{ }^{\text {todte }}$ "Kohle. 
Sogleich bei dem crsten Versuche zeigte es sich, dafs die Grummetkohle noch grofse Mengen empyreumatischer Stoffe und auch noch etwas Wasser enthalte, da sich bei ihrer Erhitzung im Kölbchen dichte Nebel von dem stechenden Geruch des Einpyreuma's in grofser Menge und auch etwas Wasserdampf entwickelte.

Die ersten Proben wurden so lange erhitzt, bis sich keine Dämpfe mehr bildeten und dann die Kohle dem freien Luftzutritt ausgesetzt.

Dieselbe erkaltete rasch und liels keine pyrophoren Eigenschaften erkennen.

Es hatte sich aber in Laufzorn die Kohle in der Zusammensetzung, wie sie vorlag, also mit ihrem Gehalte an empyreumatischen Stoffen, untzündet; das Austreiben des Empyreuma's war also der Laufzorner Beobachtung nicht entsprechend und mufste daher die Selbstentzündung der Kohle, wenn sie überhaupt sich experimentell herstellen hefse, noch mit ihrem Gehalte an empyreumatischen Stoffen gelingen.

Bei den nächsten Versuchen wurde also die Erhitzung nicht so weit getrieben. Die Grummetkohle wurde in einem Kölbchen über glühenden Kohlen so lange erhitzt, bis das Kölbchen an seinem Boden eben Rothglühhitze zeigte, und darauf die Koble, auf ein Häufchen geschültet, dem Luftzutritt preisgegeben.

Die Kohle kühlte sich rasch so weit ab, dafs man sie in den Fingern halten konnte. Nach wenigen Minuten machte sich aber darin wieder zunehmende Wärme bemerkbar und plötzlich hatten sich in dem Kohlenhäufchen rothglühende Stellen gebildet; das Glühen der Kohle dauerte nun fort, bis das Häufchen grof'sentheils eingeäschert war.

Dieser Versuch wurde oftmals wiederholt, stets mit dem gleichen Erfolge.

Da aber dieser Versuch der Erhitzung über glühenden Kohlen manche Einwürfe zu gestatten schien, erhitzte ich die Grummetkohle über dem Oelbade bis zu ciner Temperatur von 250 bis $300^{\circ}$, ohne dafs also Feuer auf irgend eine Weise direct mit derselben in Berührung kam.

Auch die so behandelte Kohle entzündete sich, auf den Tisch geschüttet und dem freien Lufizutritt preisgegeben, in der gleichen Wejse.

Es war also wirklich gelungen, zu beweisen, dafs der Grummetkohle bei hoher Tempcralur pyrophore Eigenschaften zukommen, dafs solche Kohle in der That die Eigenschaft hat, sich an der Luft selbst zu entzünden.

Dafs die Selbstentzündung nicht gelang, wenn man die empyreumatischen Stoffe ganz aus derselben entfernte, deutet 
darauf hin, dafs diese Stoffe bei der Selbstentziündung höchst wahrscheinlich eine Rolle spielen, und man wird unwillkürlich an die schon öfter beschriebenen Fälle von Selbstentzündung auf einander gehäufter wollener Oellappen erinnert.

Von besonderem Interesse schien nun die Bestimmung der Temperatur, bei welcher normales Grummet in einen ähnlichen Zustand von Verkohlung übergeführt wird, wie derselbe sich bei der Beobachtung in Laufzori ergeben hatte.

Es wurde daher iiber dem Oelbade eine kleine Menge Grummet im Reagenzgläschen erhitzt. Dabei zeigte sich bald, dafs die fragliche Temperatur so hoch liegt, dafs sie nicht mehr mit Sicherheit mit dem Quecksilberthermometer gemessen werden kann.

Es wurden daher die Schmelzpunkte von Zinn und Blei zur näheren Temperaturbestimmung benutzt und gefunden, dafs sich im Oelbade aus grünem Grummet Kohle bildet bei einer Temperatur, welche über dem Schmelzpunkte des Zinns und unter dem Schmelzpunkte des Blei's liegt. Da der Schmelzpunkt des Zinn's $280^{\circ}$ ist und der des Blei's $320^{\circ}$, liegt also die Temperatur, bei welcher das Grummet in Kohle ungewandelt wird, zwischen 280 und $320^{\circ}$.

Schliefslich versuchte ich noch, ob auch auf diesem künstlichen Wege hergestellte Grummetkohle pyrophore Eigenschaften besitze.

Eine kleine Partie grünes Grummet wurde in einem Bechergläschen im Oelbade so lange erhitzt, bis es in Kohle umgewandelt war und darauf in Form eines Häufchens auf den Tisch geschüttet. Nach wenigen Minuten hatte es sich von selbst entzündet *).

Durch obige Versuche ist der wissenschaftliche Beweis geliefert, dafs der Grummetkohle pyrophore Eigenschaften zukommen, mittels deren eine Selbstentzündung derselben unter geeigneten Verhältnissen naturnothwendig eintritt.

Freilich ist hiermit nur diejThatsache erklärt, dafs Grummetkohle sich entzünden kann, und die Untersuchung der nähteren Vorgänge der Umsetzung, mittels deren die Temperatur in einem Grummethaufen so gesteigert werden kann, dafs es zur Bildung von Kohle kommt, bleibt weiteren Untersuchungen vorbehalten.

Von gröfster Wichtigkeit ist offenbar das Moment, dafs im Innern eines grofsen Haufens Grummet von der durch chemische Umsetzung seiner Bestandtheile frei werdenden

*) Dieses Experiment dürfte sich zu einem Vorlesungsversuche trefflich eignen. 
368 Ranke, experimenteller Beweis der Möglichkeit u. s.w.

Wärme fast nichts verloren geht. Das Grummet ist ein so schlechter Wärmeleiter, dafs der in seinem Kern verkohlte Stock in Laufzorn aufsen die normale grüne Farbe des Grummets und keine wahrnehmbare Temperaturerhöhung gezeigt hatte.

Da wir aus dem Experiment gelernt haben, dafs zur Bildung von Grummetkohle eine Temperatur von ca. $300 \mathrm{Grad}$ nöthig ist, so wissen wir auch, dafs die Temperatur im Innern des Grummethaufens, in welchem factisch solche Kohle entstand, nicht weniger als ungefähr $300^{\prime \prime}$ betragen haben kann. Diese hohe Temperatur im Immern des Haufens, deren Entstehungsbeginı offenbar in Gährungsvorgängen und deren weitere Steigerung in fortschreitender chemischer Umsetzung der Bestandtheile des Grummets begründet ist, wird nur verständlich, wenn man im Auge behält, ein wie unendlich schlechter Wärmeleiter dichtgestetzles Grummet ist, und bedenkt, dafs in Folge dessen im Innern eines solchen Haufens fast sänmtliche durch die Zırsetzung frei werdende Wärme sich anhäuft, immer nur Wärme zugeführt, kaum irgend welche abgeleitet wird.

Ich kann mir an dieser Stelle nicht versagen, darauf hinzuweisen, dafs derselbe Procefs, welcher im Grummethaufen vor unsern Augen zur Bildung wirklicher Kohle führt, wohl auch bei der Eutstehung der Sleinkolılen-Flöze in der Urgeschichte unseres Planeten mitwirkend gewesen sein mag.

Ausgegeben am 14. Juni 1873. 